evaluate the impact of it and try to evaluate impact of other preventive measures.

\section{SAFE SCHOOL TRANSPORTATION OF CHILDREN SUPPORTED BY INTELLIGENT TRANSPORT SYSTEMS}

Dagmara Jankowska-Karpa, Justyna Wacowska-Slezak. Motor Transport Institute, Poland

10.1136/injuryprev-2016-042156.702

Background The article presents the evaluation results of integrated system for safe transportation of children to school done in Poland, which exploited Intelligent Transport Systems (ITS) and was developed and implemented within the European funded project Safeway2School. SW2S system included several elements, in Poland these were the following: pedestrian safety system at bus stops - Intelligent Bus Stop (IBS) and activating tags for children, bus stop inventory tool. These were supplemented with a new sign placed on a school bus and bus stops and trainings for children, parents, bus driver and bus assistant.

Methods The methods used for the evaluation of the system were pre and post speed measurements and eye-tracking experiment together with a survey carried out among drivers who used the school bus route, where selected elements of system were tested. Also a survey among users was carried out in order to measure the acceptance of the SW2S system.

Results The results of the eye tracking experiment proved that IBS attracts more attention of drivers than a regular stop. The flashing lights of IBS make drivers more aware of what is happening on the road and they notice IBS faster than a regular bus stop. The results of noticing and observing new school bus sign suggest that drivers noticed the new sign quicker than the regular bus sign which supports the assumed hypotheses.

The results of the survey support the eye-tracking outcomes while majority of drivers noticed new sign (80\%) and IBS (75\%). Majority of drivers declared that they always reduce speed when people are waiting at the bus stop or a bus approaches the stop.

The expected speed reduction of drivers on school bus route during the activity of IBS has also occurred.

Conclusions The elements tested in the implemenetation of SW2S system in Poland were positively evaluated which is of great importance for the safety and security of children and it also influences the general level of road safety.

\section{CHILD INJURIES REPORTED IN COMMUNITIES RECEIVING A ROAD INFRASTRUCTURE INTERVENTION IN DAR ES SALAAM, TANZANIA}

${ }^{1,2}$ David Ederer, ${ }^{3}$ Ayikai Mills-Tettey, ${ }^{3}$ Simon Kalolo, ${ }^{3}$ Alex Guerrero, ${ }^{3}$ Jeffrey Witte. ${ }^{1}$ Division of Unintentional Injury Prevention, Centresfor Disease Control and Prevention. Atlanta, Georgia, USA; ${ }^{2}$ Advanced Technology Logistics. Newnan, Georgia, USA; ${ }^{3}$ Amend. Dar Es Salaam, Tanzania

\subsection{6/injuryprev-2016-042156.703}

Background School Area Road Safety Assessments and Improvements (SARSAI) is a community-based road traffic injury prevention program that combines minor infrastructure improvements with road safety education at primary schools. In 2015, SARSAI was implemented in 9 schools in Dar es Salaam. We report the results of a pre-intervention population-based survey conducted to establish a baseline of child road traffic injuries in communities near schools eligible for the intervention.
Methods A household census was conducted in a sample of 22 communities around schools eligible for SARSAI, including 15,480 parents or guardians of children ages 5-16. Parents or guardians were asked basic demographic information about children in the household, and if any children had been involved in a road traffic crash in the past year. If a child had been injured or killed in a crash, a detailed questionnaire was given to the parent or guardian to collect information on the circumstances of the injury, health outcomes, and long-term functional status. Data were collected over the 3 months preceding the intervention.

Results The survey identified 199 child road traffic injuries in the past year. About $83.4 \%$ of injuries required medical attention. Three injuries resulted in permanent disability, and 7 children were killed by road traffic crashes. Legs $(38.2 \%)$, head $(22.6 \%)$, or arms $(15.6 \%)$ were the most common body areas injured. Most injuries (62.4\%) occurred while walking to school and most resulted from a crash with a motorcycle $(48 \%)$ or private car $(24.5 \%)$.

Conclusions Road traffic injuries were a substantial problem among primary school students. Interventions, such as SARSAI, to protect children walking to school from motor vehicles have the potential to reduce injuries. A post-intervention survey conducted one year after the intervention will provide insight into the effectiveness of the SARSAI program.

\section{THE ARMADILLO CLUB AS AN ELEMENT OF ROAD SAFETY AWARENESS RAISING CAMPAIGN ADDRESSED TO CHILDREN}

Maria Dabrowska-Loranc, Dagmara Jankowska-Karpa, Justyna Wacowska-Slezak, Aneta Wnuk. Motor Transport Institute, Poland

\subsection{6/injuryprev-2016-042156.704}

Background The Armadillo Club educational program was an element of the nationwide road safety awareness campaign entitled Armadillo Club Always Belts Up which has been conducted in Poland since 2005. The Armadillo Club was carried out by Motor Transport Institute in 2012/2013 school year and was targeted at kindergartens and elementary schools children and their parents. The article presents the campaign and the educational program as well as its evaluation outcomes.

Objective The objective of the whole campaign was to make the fastening of seatbelts more attractive for children and the educational program aim was to educate 4-12-year-old children in selected issues related to safety, with particular emphasis on road safety.

Results In total, 13613 children from 105 kindergartens (7030 children), 61 schools with classes 1-3 (4021 children) and 37 schools with classes 4-6 (2562) participated in the Armadillo Club. According to respondents, majority of club activities were carried out in accordance with the program guidelines (91\%). $42 \%$ of respondents considered the program as interesting and $43 \%$ - as very interesting. According to $15 \%$, certain elements were interesting, other were less interesting. $98 \%$ of respondents declared that if the campaign was to be continued, they would participate again.

Conclusions The innovative character of the whole campaign lies in the combination of awareness raising campaign with enhanced enforcement and the Armadillo Club programme. The evaluation results of both the campaign and the program were satisfactory. The post-tests show that the use rate of seat belts and child restraint systems increased by $40 \%$ in Poland since 2004. 